\title{
The metabolic benefits of different bariatric operations: what procedure to choose?
}

\author{
Alexis Sudlow ${ }^{1}$, Carel W le Roux ${ }^{2}$ and Dimitri J Pournaras ${ }^{1}$ \\ ${ }^{1}$ Department of Upper GI Surgery, Southmead Hospital, Bristol, UK \\ ${ }^{2}$ Department of Experimental Pathology, University College Dublin, Dublin, Ireland \\ Correspondence should be addressed to C le Roux: carel.leroux@ucd.ie
}

\begin{abstract}
Bariatric surgery is established as a highly effective treatment for obesity and related metabolic complications. Although once seen as a last resort for patients with obesity, given the data demonstrating the profound weight loss, improvement in comorbidity and safety, perceptions have since shifted. There is evidence from 12 RCTs demonstrating its safety and efficacy in terms of weight loss which is sustained in the long term with a resultant improvement in co-morbidity. Clinicians are increasingly recognising the importance of timely intervention to maximise the effects of bariatric surgery, particularly in light of the low likelihood of being able to adequately manage patients with medication or lifestyle interventions alone. The inclusion of bariatric surgery in the standard treatment algorithm has been a step forward in the approach to treating patients with obesity. What remains challenging for clinicians is knowing which procedure is most beneficial to patients. There is no level one data demonstrating the superiority of one procedure over another. Head to head RCTs are ongoing which may shed light on this question; however, it is likely that there is no single procedure that will be demonstrated to be the gold standard. Herein we review the most commonly performed procedures along with the evidence available to support their effects with regards to weight loss and metabolic changes along with their limitations and recognised risks. The aim is to provide a general framework to allow clinicians to take advantage of the variety of operative approaches to tailor their treatment strategy to the individual patient.
\end{abstract} Key Words

\section{Introduction}

The early concept of surgical intervention to mediate weight loss in patients suffering from obesity stemmed from the observation of the substantial and often problematic weight loss following gastrointestinal surgery for cancer. Although this effect was initially thought to be primarily the result of caloric restriction or malabsorption, our appreciation of the complex neurohormonal and metabolic effects elicited by surgery have dramatically changed and with that our understanding of the potential benefits and varying indications for bariatric surgery. It is now clear that the effects of bariatric surgery, irrespective of the procedure, work in a manner beyond the simplistic restrictive effect of a reduced stomach volume or malabsorption due to gastrointestinal bypass. The growing recognition of the complexity of obesity as a disease and the substantial associated implications of related comorbidity led to a shift in the perception of bariatric surgery. Rather than being perceived as a procedure focused predominantly on weight loss, the aim of undertaking bariatric surgery is now focused on health gain, and indeed the most significant improvements are related to its profound metabolic effects.

There has been a remarkable evolution in the field of bariatric surgery in the past 20 years due to advances 
in techniques, standardisation of practices and the near universal adoption of minimally invasive surgery (1). These changes have dramatically improved patient outcomes and safety, with the risk now on par with laparoscopic cholecystectomy (2). There is strong long-term data from the prospective Swedish Obese Subjects (SOS) study with a follow-up of over 20 years demonstrating the significant and sustained weight loss as a result of surgery and associated reduction in all-cause mortality as compared to matched controls receiving standard care (3). In light of this data, it could be reasonably argued that in some patients, it may be more of a risk not to have bariatric surgery than to continue living with the implications of obesity. Moreover, evidence from more than ten randomised controlled trials comparing bariatric surgery to medical care have consistently demonstrated more favourable results with regards to weight loss, weight loss maintenance and control of co-morbidity, particularly type two diabetes (T2DM) $(4,5,6,7,8,9,10,11,12,13$, $14,15)$.

Bariatric surgery has been demonstrated as a powerful tool in the treatment of obesity with multisystemic effects, acting both within the GI tract and centrally to modify the underlying disease process. With mounting evidence supporting not only its safety but also its superiority as a treatment over any currently available medical treatment, there has been a gradual but persistently increasing focus on its role in treating obesity. Quite rightly, bariatric surgery is no longer viewed as extreme nor as a last resort, but as an approach that should be considered as a standard treatment option in those with significant disease and as such has been incorporated into the treatment guidelines for patients suffering from T2DM by the ADA and IDF $(16,17)$.

Although there is good evidence to support bariatric surgery as a treatment for obesity, what remains to be seen is what is the most effective form of surgery to achieve a sustained, long-term weight loss with resultant control of obesity-related comorbidity. With regards to the metabolic effects of each procedure, it is again unclear if one operation in particular produces a more profound response and normalisation of metabolic changes associated with obesity. There are several considerations and this question is not easily answered nor is there any high-quality, level one evidence from RCTs at present to suggest the superiority of one procedure over another. Previous studies have largely focused on a comparison between bariatric surgery and medical treatment. While they provided much needed answers early on, what is now needed are RCTs comparing the long-term metabolic effects of various surgical procedures. There are two largescale studies ongoing at present comparing the most commonly performed operations, By-Band-Sleeve (BBS) and Bypass Equipoise Sleeve Trial (BEST), which may demonstrate the superiority of a specific type operation. Once reported, these trials may provide some clarity; however, clinicians need to provide treatment to the growing population of patients suffering from obesity today $(18,19)$.

The Global Registry data published by IFSO covering 51 countries world-wide illustrates the variety of procedures performed and allows for the identification of trends with regards to the popularity of specific operations. Data collected from 2014 to 2018 indicated that the two most commonly performed procedures were sleeve gastrectomy (45.9\%) and Roux-en-Y gastric bypass (38.3\%). There was a general trend indicating the increasing popularity of sleeve gastrectomy and significant decreases in the number of gastric band procedures. The number of operations recognised by IFSO is slowly increasing and now includes sleeve gastrectomy (SG), adjustable gastric banding (AGB), biliopancreatic diversion with duodenal switch (BPD/DS), one anastomosis gastric bypass (OAGB) and Roux-en-Y gastric bypass (RYGB) (1).

\section{Sleeve gastrectomy}

Sleeve gastrectomy (SG) was initially conceived as an operation which would be part of a two-stage duodenal switch procedure; however, the recognition of the substantial weight loss produced by the initial operation involving the removal of a segment of the stomach prompted surgeons to undertake it as a procedure in its own right. The metabolic effects of SG are thought to be the result of a combination of increased GLP-1 and PYY as well as decreased ghrelin following resection of the gastric fundus $(20,21)$. Alterations in bile acids have also been demonstrated to be a significant contributory factor in animal models following SG (22). Since its adoption as a standalone procedure, SG has increased in popularity with data from a 2013 global survey indicating that it accounted for $37 \%$ of bariatric procedures, increasing to $45.9 \%$ in $2018(1,23)$. One of the main drivers of this trend is purported to be the widely held but perhaps inaccurate perception that it is technically a less complex procedure than RYGB with a lower risk of postoperative complications. Evidence from two RCTs demonstrated that there was no significant difference in BMI over 5 years as compared to RYGB $(24,25)$. With regards to 
control of comorbidity, namely T2DM, there is a general tendency to view RYGB as a superior procedure; however, at present, there have been no trials demonstrating a significant difference in the remission rate of T2DM. Both procedures have evidence suggesting similar remission rates, and perhaps more importantly, comparable longterm control (26). There are a number of previous studies which have not been adequately powered to demonstrate superiority of RYGB vs SG for treating T2DM; however, there is a suggestion that glycaemic control is better with RYGB and it may be that larger studies in the future will demonstrate a difference. From a practical point of view, there is a widely recognised need to increase access to bariatric surgery at a time where rising global rates of obesity far outstrip the ability of any healthcare system to provide access to care. The availability of a procedure which is arguably less technically demanding, faster and thus far demonstrated to produce similar weight loss and control of complication to RYGB should be seen as positive with regards to its potential to allow for an increase in the number of procedures performed. With this in mind, there are also several reasoned arguments against the adoption of SG in certain patient groups including the worsening of pre-existing or development of de novo gastro-oesophageal reflux and concerns about the risk of subsequent Barrett's metaplasia. This concern is not unfounded as both comparative studies, SM-BOSS and SLEEVEPASS, demonstrated a significant number of reoperations following SG due to severe reflux compared to RYGB $(24,25)$. A further study with a follow-up period of more than 10 years suggested a high incidence of both hiatal hernias and Barrett's in patients following SG (27). Although the presence of reflux is not an absolute contraindication for SG, the risk merits thoughtful consideration and should be discussed with the patient. It may also be advisable to undertake further investigations in the presence of reflux symptoms including upper GI endoscopy, manometry or $\mathrm{pH}$ studies.

\section{Adjustable gastric band}

Accounting for between 40 and $60 \%$ of bariatric procedures between 2003 and 2008, the popularity of adjustable gastric banding (AGB) has seen a precipitous decline world-wide. AGBs now form a mere 5\% of procedures performed between 2014 and $2018(1,28)$. The ongoing use of AGB as a durable and effective treatment for obesity is by all accounts polarising and can prove to be a highly emotive topic. Many would argue that AGB has been entirely superseded by the more commonly performed procedures, given the more significant and sustained weight loss and perception that it is less effective with regards to inducing metabolic change and control of T2DM. The exact mechanisms by which gastric banding mediates weight loss are incompletely understood; however, it is suggested to invoke changes beyond what would be described as the basic concept of restriction (29). The main effects resulting from AGB appear to be prolonged satiety, even during periods of fasting; however, it is unclear how this is mediated (29). There are, however, some mechanistic studies which have suggested that several of the critical neurohormonal changes, many of which have been demonstrated to occur in a weight loss-independent manner following bypass procedures or SG, do not occur following insertion of an AGB even following equivalent weight loss (30). Critically, these changes have been demonstrated to have a significant impact on appetite, satiety, energy regulation and glycaemic control, prompting some to question the role of AGB in modifying the metabolic effects of obesity. In spite of this, it is unfair to summarily dismiss AGB entirely, as this would be denying the fact that it is for this procedure that we have the most robust longterm data to support its potential to produce sustained weight loss in carefully selected patients. Moreover, the SOS study suggested the $15 \%$ weight loss caused by the AGB had the same mortality benefit as the $25 \%$ weight loss as a result of RYGB (3). It is also a very safe procedure with low perioperative risk. Arguably, most bariatric operations have a good safety profile; however, this may be worth considering in patients who are particularly risk adverse or high risk themselves. The benefits of AGB are often overshadowed for many in the field by the general view that it is a procedure resulting in inadequate weight loss and frequently requires removal or revision. Although there have been studies demonstrating high rates of complications requiring reoperation or revision which support this view, the experience in high-volume centres with a regular follow-up would suggest that better outcomes are achievable. A retrospective study of more than 2000 patients reported a reoperation rate of $4.5 \%$ over a 9-year follow-up period with removal required in only $1.5 \%$ of cases (31). In all areas of surgery but perhaps in bariatric surgery more so than any other, careful, considered patient selection and subsequent follow-up are critical to the success of a procedure, a fact illustrated by the broad experience with AGB. It is understandable given the often inferior weight loss following $\mathrm{AGB}$ that it is a procedure widely seen as inferior to other 
bariatric operations. On the other hand, it can be argued that poor weight loss is not an inevitability but rather the result of our inability to predict the effect of the band prior to surgery, suboptimal patient selection and inadequate follow-up. The possibility of achieving very good outcomes with AGB was illustrated by data from an RCT over a follow-up period of 2 years, demonstrating that, in comparison to lifestyle changes, patients undergoing AGB had a mean weight loss of 20.7 vs $1.7 \%$. Looking specifically at the metabolic effects, in patients with T2DM of a short duration, there was a 73\% remission rate as compared to $13 \%$ with medical care (4). These rates of weight loss and T2DM remission are noteworthy as they are similar to what is expected with RYGB. This evidence must be considered in the context that patients were followed up with band volume adjustment as necessary every 4-6 weeks which most would agree is not the current standard of care. This evidence would suggest that AGB can produce meaningful and sustained weight loss as well as control of T2DM in carefully prepared patients who are followed up closely. In addition, one must take into account the relative reversibility of the procedure which may be a significant factor in the decision-making process for many patients. The perception of AGBs may require re-thinking in an era where there is significant interest in the use of medical devices together with modern pharmacotherapy for the treatment of obesity and diabetes. Within this context, there may be a place for the band to be reinterpreted as a medical device that is placed laparoscopically rather than a standalone bariatric surgery procedure.

\section{Biliopancreatic diversion and duodenal switch (BPD/DS)}

Generally considered as a treatment option for patients suffering from severe obesity and not widely performed, biliopancreatic diversion and duodenal switch (BPD/DS) accounts for a minute percentage of bariatric procedures undertaken world-wide. It is generally accepted that $\mathrm{BPD} / \mathrm{DS}$ results in greater weight loss which is sustained long term with resultant improvement in co-morbidity with its effects largely potentiated by a powerful incretin effect resulting in increased GLP-1, PYY and alterations in bile acid metabolism $(32,33)$. The fact that it is an infrequently performed procedure reflects that it is not only technically challenging but also associated with a considerable postoperative risk of nutritional deficiencies. Weight loss maintenance following BPD/DS has been demonstrated in multiple studies to be even greater than RYGB or SG, in the region of $>70 \%$ excess body weight loss (EBWL) or $40 \%$ total weight loss (34). The impact of BPD/ DS with regards to T2DM remission is profound with up to $95 \%$ of patients undergoing the procedure maintaining remission at 2 years (6). The impressive metabolic effects cannot be looked at in isolation or without taking in to account the considerable perioperative risk as well as the need for long-term nutritional follow-up and supplementation. Although overall risk remains low, $\mathrm{BPD} / \mathrm{DS}$ is associated with the highest 30-day mortality and 1-year complication rates of any bariatric procedure with anastomotic leak and PE being the most common early complications. Moreover in the long term, the percentage of patients requiring reoperation is significant, including up to $10 \%$ for nutritional deficiencies (35). Management of nutrition in the postoperative period requires careful monitoring, as iron deficiency anaemia and deficiencies in fat-soluble vitamins, vitamin 1/B12 and folate are not uncommon. Supplementation is challenging in some patients and they may remain refractory to treatment, necessitating revisional surgery (36). Worryingly, patients have been reported to develop severe and, in some cases, irreversible complications as a result of these deficiencies including night blindness, peripheral neuropathy and Wernicke's encephalopathy. It is not unsurprising, given the increased perioperative risk and the seriousness of the potential nutritional complications, that this procedure remains the one carried out in only a limited number of centres despite the significant weight loss and T2DM remission rates.

\section{One anastomosis gastric bypass}

The one anastomosis gastric bypass (OAGB) has alternatively been called the 'mini bypass' owing to the fact that it is seen as a simplified modification of the RYGB. This procedure is considered less technically challenging as there is only one anastomosis which has been professed by its proponents as one of its main advantages. Given the similarities with RYGB with a component involving bypass of the proximal small bowel, the metabolic effects are thought to be largely mediated through an incretin effect with increased GLP-1; however, studies at present are largely limited to animal studies (37). Patients undergoing OAGB are thought to be at a lower risk of anastomotic leak and perioperative complications, including chronic abdominal pain which has been associated with the jejuno-jejunal anastomosis formed in a RYGB.

This work is licensed under a Creative Commons Attribution-NonCommercial-NoDerivatives 4.0 Internationab ticense.ifica com at 04/26/2023 09:58:42AM 
As a relatively new procedure in comparison to the more widely adopted approaches, longer-term data to support its use is limited. A recent randomised controlled trial with a 2-year follow-up period suggested that OAGB was not inferior to RYGB with regards to weight loss or rates of T2DM remission; however, there was a difference with regards to complications (38). Following OAGB, there were nearly twice as many complications, in particular, nutritional deficiencies. The number of patients affected by nutritional deficiency was not only significant but stood in stark contrast to the zero seen following RYGB. The incidence of diarrhoea as well as steatorrhea was significantly higher following OAGB. What remains to be seen is the long-term success of the procedure, and future studies will need to be carried out in order to determine whether the weight loss and metabolic effects are sustained in the long term. With regards to nutritional deficiencies, trials looking at alteration of the limb length have been suggested. As with all bariatric procedures, the adoption of OAGB is not free from controversy. There are concerns given the configuration of the anastomosis regarding bile reflux in to the gastric pouch with studies demonstrating a significant increase in postoperative rates of reflux and oesophagitis compared to RYGB. Given these findings, it is important to take these factors into consideration when discussing the choice of operative procedure with patients who have a history of reflux. Endoscopic findings in postoperative patients demonstrating bile acid reflux have also raised concerns about the potential implication for the development of gastric or oesophageal malignancy. At present, there are no studies to demonstrate that OAGB is related to the development of dysplastic changes; however, in the absence of long-term safety data, it raises the question whether surveillance endoscopy is indicated until we have an answer.

\section{Roux-en-Y gastric bypass}

In recent years, the popularity of RYGB has fallen in favour of SG. It is regarded as a reasonably challenging procedure from a technical point of view as it requires the formation of two anastomoses which may, in part, account for the decline in the numbers being performed world-wide. In spite of this, RYGB is generally regarded as a procedure that produces reliable weight loss with an acceptable risk profile and, crucially, a significant amount of research to support its use. It is one of the procedures with the most level one evidence demonstrating its efficacy with regards to long-term weight loss and as a treatment for T2DM.
Similarly, the mechanisms by which RYGB act have been extensively investigated and although still incompletely understood appear to act, in part, due to alterations in neurohormonal signalling mediated by GLP-1 and PYY as well as alterations in bile acid metabolism (20, $39,40)$. Although there is no level one data at present to suggest its superiority over any other procedure, there are certain indications which would favour its use, such as in the significant subset of patients with obesity who also suffer from gastro-oesophageal reflux. In these patients, RYGB may be a particularly pragmatic choice given its efficacy as a treatment for reflux in its own right. Following any bariatric procedures, there is the risk of developing nutritional deficiencies; however, this is less common than in OAGB and BPD/DS $(38,41)$. There are complications specific to RYGB which must be noted, namely internal herniation which may result in subsequent bowel ischaemia. Long-term data would also suggest that a subgroup of patients report chronic abdominal pain following RYGB which can be difficult to manage and may impact on health-related quality of life. Additionally, the anatomical changes in patients following RYGB result in limited access to the remnant stomach and duodenum which may be problematic in patients with gallstone disease should the need for ERCP arise. As with all procedures, there are well-documented risks associated with RYGB; however, it remains a standard choice in many centres, a choice justified by the high-quality, long-term evidence to support its use which is unavailable for the less well-established procedures.

\section{Conclusion}

Bariatric surgery in its many forms offers patients significant, long-term weight loss, control of comorbidity and, most important of all, improved long-term mortality. There has been a revolution in the field with the transition from open to laparoscopic procedures which has not only generally improved outcomes but has allowed surgeons to broaden the variety of procedures they can safely perform and offer patients. While there are still many unanswered questions regarding the exact mechanism by which these procedures work and on a practical level, which is the best, irrespective of the outcomes, we expect that the BBS and BEST studies previously mentioned will provide critical, comparative data. In addition to the highly anticipated reporting of these studies, there is a growing body of evidence to support the notion that regardless of the surgical procedure, these are operations 
Table 1 Summary of the most commonly performed procedures.

\begin{tabular}{|c|c|c|c|c|}
\hline Procedure & Mechanism of action & $\begin{array}{l}\text { Expected } \% \text { total } \\
\text { body weight loss } \\
\text { at } 2 \text { years }\end{array}$ & $\begin{array}{l}\text { Effect on } \\
\text { T2DM }\end{array}$ & $\begin{array}{l}\text { Common side } \\
\text { effects/complications }\end{array}$ \\
\hline Sleeve gastrectomy (SG) & $\begin{array}{l}\uparrow \text { GLP-1, PYY, insulin secretion, bile } \\
\text { acid secretion and satiety } \\
\downarrow \text { Ghrelin, insulin resistance and } \\
\text { hunger }\end{array}$ & $-26 \%$ & ++ & $\begin{array}{l}\text { + Nutritional deficiency risk } \\
\text { GORD } \\
\text { Staple line leak } \\
\uparrow \text { Barrett's oesophagus }\end{array}$ \\
\hline $\begin{array}{l}\text { Adjustable gastric } \\
\text { band (AGB) }\end{array}$ & $\begin{array}{l}\downarrow \text { Hunger, meal frequency and } \\
\text { caloric intake }\end{array}$ & -15 to $20 \%$ & + & $\begin{array}{l}\text { GORD } \\
\text { Dysphagia } \\
\text { Band slippage } \\
\text { Band erosion } \\
\text { Band intolerance }\end{array}$ \\
\hline $\begin{array}{l}\text { Biliopancreatic diversion } \\
\text { with duodenal switch } \\
\text { (BPD/DS) }\end{array}$ & $\begin{array}{l}\uparrow \text { GLP-1, PYY, insulin secretion, bile } \\
\text { acid secretion and satiety } \\
\downarrow \text { Ghrelin, hunger, insulin } \\
\text { resistance, hepatic glucose } \\
\text { production and intestinal } \\
\text { absorption }\end{array}$ & $-38 \%$ & +++ & $\begin{array}{l}+++ \text { Nutritional deficiency risk } \\
\text { Anastomotic leak } \\
\text { Internal hernia }\end{array}$ \\
\hline $\begin{array}{l}\text { One anastomosis gastric } \\
\text { bypass (OAGB) }\end{array}$ & $\begin{array}{l}\uparrow \text { GLP-1, insulin secretion and } \\
\text { satiety } \\
\downarrow \text { Hunger, insulin resistance and } \\
\text { hepatic glucose production }\end{array}$ & $-37 \%$ & ++ & $\begin{array}{l}\text { ++ Nutritional deficiency risk } \\
\text { Diarrhoea } \\
\text { Steatorrhea } \\
\text { Internal hernia } \\
\text { ? Biliary reflux }\end{array}$ \\
\hline $\begin{array}{l}\text { Roux en Y gastric bypass } \\
\text { (RYGB) }\end{array}$ & $\begin{array}{l}\uparrow \text { GLP-1, PYY, insulin secretion, bile } \\
\text { acid secretion and satiety } \\
\downarrow \text { Hunger, insulin resistance and } \\
\text { hepatic glucose production }\end{array}$ & -30 to $35 \%$ & ++ & $\begin{array}{l}\text { + Nutritional deficiency risk } \\
\text { Chronic abdominal pain } \\
\text { Internal hernia }\end{array}$ \\
\hline
\end{tabular}

that are all considered safe and effective treatments for obesity and related complications (Table 1). Beyond direct comparisons between procedures, further research is required to determine if variations of specific operations may improve outcomes as has been investigated in various bypass procedures, both RYGB and OAGB, to determine if changes of the length of proximal bowel bypassed can improve outcomes or reduce postoperative complications $(42,43,44)$. Assessment of the value of each individual procedure is complex, requiring evaluation on the basis of factors beyond weight loss alone, namely the metabolic effects as these are most likely to contribute to improvements in long-term outcomes. Given the heterogeneity of the population affected by obesity and the varying impact it has on individual patients, it may be that we never identify a 'gold standard', single operation that is best for all patients. Rather than seeing this as problematic, the variety of surgical procedures available should be viewed as an opportunity to provide treatment tailored to the patient just as there is no single operation for oesophageal cancer or hernias that suits all. Taking this point of view, clinicians equally should be encouraged by the availability of new approaches such as robotic surgery and non-surgical approaches on the horizon such as endoscopic techniques which will likely further increase the number of patients to which a bariatric procedure will be suitable for. Moreover, our understanding of the underlying disease process is constantly evolving and we may come to recognise that obesity in itself may be a heterogenous entity. Undoubtedly, head to head trials of procedures will broadly improve our understanding of each operation, but the greatest value will be in coming to understand what each can offer individual patients, allowing us to deliver precision treatment for obesity the right operation at the right time in combination with adjuvant treatment. Clinicians now have a greater understanding of the disease and mechanisms of action of surgery, combined with solid data from studies and registries regarding safety and efficacy. This brings us to an exciting time in the treatment of obesity, allowing the provision of better care for patients suffering from this disease than at any time in the past.

\section{Declaration of interest}

C I R reports receiving grants from Science Foundation Ireland, grants from Health Research Board, grants from AnaBio during the conduct of the study; other from NovoNordisk, other from GI Dynamics, personal fees from Eli Lilly, grants and personal fees from Johnson and Johnson, personal fees from Sanofi Aventis, personal fees from Astra Zeneca, personal fees from Janssen, personal fees from Bristol-Myers Squibb and personal fees from Boehringer-Ingelheim, outside the submitted work and shares in Keyron. D J P reports receiving honoraria from NovoNordisk and Johnson and Johnson for lectures. A S has nothing to declare. (c) 2020 The authors Published by Bioscientifica Ltd
This work is licensed under a Creative Commons Attribution-NonCommercial-NoDerivatives 4.0 Internationab sicense.ifica . com at 04/26/2023 09:58:42AM 


\section{Funding}

This work did not receive any specific grant from any funding agency in the public, commercial or not-for-profit sector.

\section{References}

1 Welbourn R, Hollyman M, Kinsman R, Dixon J, Liem R, Ottosson J, Ramos A, Våge V, Al-Sabah S, Brown W, et al. Bariatric surgery worldwide: baseline demographic description and one-year outcomes from the fourth IFSO Global Registry Report 2018. Obesity Surgery 201929 782-795. (https://doi.org/10.1007/s11695-018-3593-1)

2 Longitudinal Assessment of Bariatric Surgery (LABS) Consortium, Flum DR, Belle SH, King WC, Wahed AS, Berk P, Chapman W, Pories W, Courcoulas A, McCloskey C, et al. Perioperative safety in the longitudinal assessment of bariatric surgery. New England Journal of Medicine 2009361 445-454. (https://doi.org/10.1056/ NEJMoa0901836)

3 Sjöström L, Narbro K, Sjöström CD, Karason K, Larsson B, Wedel H, Lystig T, Sullivan M, Bouchard C, Carlsson B, et al. Effects of bariatric surgery on mortality in Swedish obese subjects. New England Journal of Medicine 2007357 741-752. (https://doi.org/10.1056/ NEJMoa066254)

4 Dixon JB, O'Brien PE, Playfair J, Chapman L, Schachter LM, Skinner S, Proietto J, Bailey M \& Anderson M. Adjustable gastric banding and conventional therapy for type 2 diabetes: a randomized controlled trial. JAMA 2008299 316-323. (https://doi.org/10.1001/ jama.299.3.316)

5 Schauer PR, Bhatt DL, Kirwan JP, Wolski K, Aminian A, Brethauer SA, Navaneethan SD, Singh RP, Pothier CE, Nissen SE, et al. Bariatric surgery versus intensive medical therapy for diabetes -5 -year outcomes. New England Journal of Medicine 2017376 641-651. (https://doi.org/10.1056/NEJMoa1600869)

6 Mingrone G, Panunzi S, De Gaetano A, Guidone C, Iaconelli A, Leccesi L, Nanni G, Pomp A, Castagneto M, Ghirlanda G, et al. Bariatric surgery versus conventional medical therapy for type 2 diabetes. New England Journal of Medicine 2012366 1577-1585. (https://doi.org/10.1056/NEJMoa1200111)

7 Ikramuddin S, Korner J, Lee WJ, Connett JE, Inabnet WB, Billington CJ, Thomas AJ, Leslie DB, Chong K, Jeffery RW, et al. Roux-en-Y gastric bypass vs intensive medical management for the control of type 2 diabetes, hypertension, and hyperlipidemia: the Diabetes Surgery Study randomized clinical trial. JAMA 2013309 2240-2249. (https://doi.org/10.1001/jama.2013.5835)

8 Kashyap SR, Bhatt DL, Wolski K, Watanabe RM, Abdul-Ghani M, Abood B, Pothier CE, Brethauer S, Nissen S, Gupta M, et al. Metabolic effects of bariatric surgery in patients with moderate obesity and type 2 diabetes: analysis of a randomized control trial comparing surgery with intensive medical treatment. Diabetes Care 201336 2175-2182. (https://doi.org/10.2337/dc12-1596)

9 Courcoulas AP, Goodpaster BH, Eagleton JK, Belle SH, Kalarchian MA, Lang W, Toledo FG \& Jakicic JM. Surgical vs medical treatments for type 2 diabetes mellitus: a randomized clinical trial. JAMA Surgery 2014149 707-715. (https://doi. org/10.1001/jamasurg.2014.467)

10 Halperin F, Ding SA, Simonson DC, Panosian J, Goebel-Fabbri A, Wewalka M, Hamdy O, Abrahamson M, Clancy K, Foster K, et al. Roux-en-Y gastric bypass surgery or lifestyle with intensive medical management in patients with type 2 diabetes: feasibility and 1-year results of a randomized clinical trial. JAMA Surgery 2014149 716-726. (https://doi.org/10.1001/jamasurg.2014.514)

11 Simonson DC, Halperin F, Foster K, Vernon A \& Goldfine AB. Clinical and patient-centered outcomes in obese patients with type 2 diabetes 3 years after randomization to Roux-en-Y gastric bypass surgery versus intensive lifestyle management: the SLIMM-T2D study. Diabetes Care 201841 670-679. (https://doi.org/10.2337/dc170487)

12 Liang Z, Wu Q, Chen B, Yu P, Zhao H \& Ouyang X. Effect of laparoscopic Roux-en-Y gastric bypass surgery on type 2 diabetes mellitus with hypertension: a randomized controlled trial. Diabetes Research and Clinical Practice 2013101 50-56. (https://doi. org/10.1016/j.diabres.2013.04.005)

13 Wentworth JM, Playfair J, Laurie C, Ritchie ME, Brown WA, Burton P, Shaw JE \& O'Brien PE. Multidisciplinary diabetes care with and without bariatric surgery in overweight people: a randomised controlled trial. Lancet: Diabetes and Endocrinology 20142 545-552. (https://doi.org/10.1016/S2213-8587(14)70066-X)

14 Cummings DE, Arterburn DE, Westbrook EO, Kuzma JN, Stewart SD, Chan CP, Bock SN, Landers JT, Kratz M, Foster-Schubert KE, et al. Gastric bypass surgery vs intensive lifestyle and medical intervention for type 2 diabetes: the CROSSROADS randomised controlled trial. Diabetologia 201659 945-953. (https://doi.org/10.1007/s00125-0163903-x)

15 Parikh M, Chung M, Sheth S, McMacken M, Zahra T, Saunders JK, Ude-Welcome A, Dunn V, Ogedegbe G, Schmidt AM, et al. Randomized pilot trial of bariatric surgery versus intensive medical weight management on diabetes remission in type 2 diabetic patients who do NOT meet NIH criteria for surgery and the role of soluble RAGE as a novel biomarker of success. Annals of Surgery 2014260 617-622; discussion 622-614. (https://doi.org/10.1097/ SLA.0000000000000919)

16 Rubino F, Nathan DM, Eckel RH, Schauer PR, Alberti KG, Zimmet PZ, Del Prato S, Ji L, Sadikot SM, Herman WH, et al. Metabolic surgery in the treatment algorithm for type 2 diabetes: a joint statement by international diabetes organizations. Diabetes Care 201639 861-877. (https://doi.org/10.2337/dc16-0236)

17 Dixon JB, Zimmet P, Alberti KG, Rubino F \& International Diabetes Federation Taskforce on Epidemiology and Prevention. Bariatric surgery: an IDF statement for obese type 2 diabetes. Diabetic Medicine 201128 628-642. (https://doi.org/10.1111/j.14645491.2011.03306.x)

18 Hedberg S, Olbers T, Peltonen M, Österberg J, Wirén M, Ottosson J, Thorell A \& BEST Study Group. BEST: bypass equipoise sleeve trial; rationale and design of a randomized, registry-based, multicenter trial comparing Roux-en-Y gastric bypass with sleeve gastrectomy. Contemporary Clinical Trials 201984 105809. (https://doi. org/10.1016/j.cct.2019.07.001)

19 Rogers CA, Reeves BC, Byrne J, Donovan JL, Mazza G, Paramasivan S, Andrews RC, Wordsworth S, Thompson J, Blazeby JM, et al. Adaptation of the by-band randomized clinical trial to by-bandsleeve to include a new intervention and maintain relevance of the study to practice. British Journal of Surgery 2017104 1207-1214. (https://doi.org/10.1002/bjs.10562)

20 Pournaras DJ \& le Roux CW. Obesity, gut hormones, and bariatric surgery. World Journal of Surgery 200933 1983-1988. (https://doi. org/10.1007/s00268-009-0080-9)

21 Kalinowski P, Paluszkiewicz R, Wróblewski T, Remiszewski P, Grodzicki M, Bartoszewicz Z \& Krawczyk M. Ghrelin, leptin, and glycemic control after sleeve gastrectomy versus Roux-en-Y gastric bypass-results of a randomized clinical trial. Surgery for Obesity and Related Diseases 201713 181-188. (https://doi.org/10.1016/j. soard.2016.08.025)

22 Pournaras DJ \& le Roux CW. Are bile acids the new gut hormones? Lessons from weight loss surgery models. Endocrinology 2013154 2255-2256. (https://doi.org/10.1210/en.2013-1383)

23 Angrisani L, Santonicola A, Iovino P, Formisano G, Buchwald H \& Scopinaro N. Bariatric surgery worldwide 2013. Obesity Surgery 2015 25 1822-1832. (https://doi.org/10.1007/s11695-015-1657-z)

24 Peterli R, Wölnerhanssen BK, Peters T, Vetter D, Kröll D, Borbély Y, Schultes B, Beglinger C, Drewe J, Schiesser M, et al. Effect of laparoscopic sleeve gastrectomy vs laparoscopic Roux-en-Y gastric 
bypass on weight loss in patients with morbid obesity: the SM-BOSS randomized clinical trial. JAMA 2018319 255-265. (https://doi. org/10.1001/jama.2017.20897)

25 Salminen P, Helmiö M, Ovaska J, Juuti A, Leivonen M, PeromaaHaavisto P, Hurme S, Soinio M, Nuutila P \& Victorzon M. Effect of laparoscopic sleeve gastrectomy vs laparoscopic Roux-en-Y gastric bypass on weight loss at 5 years among patients with morbid obesity: the SLEEVEPASS randomized clinical trial. JAMA 2018319 241-254. (https://doi.org/10.1001/jama.2017.20313)

26 Pournaras DJ, Aasheim ET, Søvik TT, Andrews R, Mahon D, Welbourn R, Olbers T \& le Roux CW. Effect of the definition of type II diabetes remission in the evaluation of bariatric surgery for metabolic disorders. British Journal of Surgery 201299 100-103. (https://doi.org/10.1002/bjs.7704)

27 Felsenreich DM, Kefurt R, Schermann M, Beckerhinn P, Kristo I, Krebs M, Prager G \& Langer FB. Reflux, sleeve dilation, and Barrett's esophagus after laparoscopic sleeve gastrectomy: longterm follow-up. Obesity Surgery 201727 3092-3101. (https://doi. org/10.1007/s11695-017-2748-9)

28 Buchwald H \& Oien DM. Metabolic/bariatric surgery Worldwide 2008. Obesity Surgery 200919 1605-1611. (https://doi.org/10.1007/ s11695-009-0014-5)

29 Dixon AF, Dixon JB \& O'Brien PE. Laparoscopic adjustable gastric banding induces prolonged satiety: a randomized blind crossover study. Journal of Clinical Endocrinology and Metabolism 200590 813-819. (https://doi.org/10.1210/jc.2004-1546)

30 Pournaras DJ, Osborne A, Hawkins SC, Vincent RP, Mahon D, Ewings P, Ghatei MA, Bloom SR, Welbourn R \& le Roux CW. Remission of type 2 diabetes after gastric bypass and banding: mechanisms and 2 year outcomes. Annals of Surgery 2010252 966-971. (https://doi.org/10.1097/SLA.0b013e3181efc49a)

31 Giet L, Baker J, Favretti F, Segato G, Super P, Singhal R \& Ashton D. Medium and long-term results of gastric banding: outcomes from a large private clinic in UK. BMC Obesity 20185 12. (https://doi. org/10.1186/s40608-018-0189-1)

32 Scopinaro N, Marinari GM, Camerini GB, Papadia FS \& Adami GF. Specific effects of biliopancreatic diversion on the major components of metabolic syndrome: a long-term follow-up study. Diabetes Care 200528 2406-2411. (https://doi.org/10.2337/diacare.28.10.2406)

33 Valverde I, Puente J, Martín-Duce A, Molina L, Lozano O, Sancho V, Malaisse WJ \& Villanueva-Peñacarrillo ML. Changes in glucagonlike peptide-1 (GLP-1) secretion after biliopancreatic diversion or vertical banded gastroplasty in obese subjects. Obesity Surgery 2005 15 387-397. (https://doi.org/10.1381/0960892053576613)

34 Buchwald H, Estok R, Fahrbach K, Banel D, Jensen MD, Pories WJ, Bantle JP \& Sledge I. Weight and type 2 diabetes after bariatric surgery: systematic review and meta-analysis. American Journal of Medicine 2009 122 248.e5-256.e5. (https://doi.org/10.1016/j.amjmed.2008.09.041)

35 Bolckmans R \& Himpens J. Long-term ( $>10 \mathrm{yrs}$ ) outcome of the laparoscopic biliopancreatic diversion with duodenal switch.
Annals of Surgery 2016264 1029-1037. (https://doi.org/10.1097/ SLA.0000000000001622)

36 Homan J, Betzel B, Aarts EO, Dogan K, van Laarhoven KJ, Janssen IM \& Berends FJ. Vitamin and mineral deficiencies after biliopancreatic diversion and biliopancreatic diversion with duodenal switch - the rule rather than the exception. Obesity Surgery 201525 1626-1632. (https://doi.org/10.1007/s11695-015-1570-5)

37 Zubiaga L, Abad R, Ruiz-Tovar J, Enriquez P, Vílchez JA, Calzada M, Pérez De Gracia JA \& Deitel M. The effects of one-anastomosis gastric bypass on glucose metabolism in goto-Kakizaki rats. Obesity Surgery 201626 2622-2628. (https://doi.org/10.1007/s11695-016-2138-8)

38 Robert M, Espalieu P, Pelascini E, Caiazzo R, Sterkers A, Khamphommala L, Poghosyan T, Chevallier JM, Malherbe V, Chouillard E, et al. Efficacy and safety of one anastomosis gastric bypass versus Roux-en-Y gastric bypass for obesity (YOMEGA): a multicentre, randomised, open-label, non-inferiority trial. Lancet 2019393 1299-1309. (https://doi.org/10.1016/S01406736(19)30475-1)

39 Pournaras DJ, Aasheim ET, Bueter M, Ahmed AR, Welbourn R, Olbers T \& le Roux CW. Effect of bypassing the proximal gut on gut hormones involved with glycemic control and weight loss. Surgery for Obesity and Related Diseases 20128 371-374. (https://doi. org/10.1016/j.soard.2012.01.021)

40 Pournaras DJ, Glicksman C, Vincent RP, Kuganolipava S, AlaghbandZadeh J, Mahon D, Bekker JH, Ghatei MA, Bloom SR, Walters JR, et al. The role of bile after Roux-en-Y gastric bypass in promoting weight loss and improving glycaemic control. Endocrinology 2012153 3613-3619. (https://doi.org/10.1210/en.2011-2145)

41 Risstad H, Søvik TT, Engström M, Aasheim ET, Fagerland MW, Olsén MF, Kristinsson JA, le Roux CW, Bøhmer T, Birkeland KI, et al. Five-year outcomes after laparoscopic gastric bypass and laparoscopic duodenal switch in patients with body mass index of 50 to 60: a randomized clinical trial. JAMA Surgery 2015150 352-361. (https:// doi.org/10.1001/jamasurg.2014.3579)

42 Svanevik M, Risstad H, Hofsø D, Schou CF, Solheim B, Søvik TT, Kristinsson J, Hjelmesæth J, Mala T \& Sandbu R. Perioperative outcomes of proximal and distal gastric bypass in patients with BMI ranged $50-60 \mathrm{~kg} / \mathrm{m}(2)$ - a double-blind, randomized controlled trial. Obesity Surgery 201525 1788-1795. (https://doi.org/10.1007/s11695015-1621-y)

43 Pinheiro JS, Schiavon CA, Pereira PB, Correa JL, Noujaim P \& Cohen R. Long-long limb Roux-en-Y gastric bypass is more efficacious in treatment of type 2 diabetes and lipid disorders in super-obese patients. Surgery for Obesity and Related Diseases 20084 521-525; discussion 526-527. (https://doi.org/10.1016/j. soard.2007.12.016)

44 Dogan K, Homan J, Aarts EO, van Laarhoven CJ, Janssen IM \& Berends FJ. A short or a long Roux limb in gastric bypass surgery: does it matter? Surgical Endoscopy 201731 1882-1890. (https://doi. org/10.1007/s00464-016-5188-z)

Received in final form 24 December 2019

Accepted 9 January 2020

Accepted Manuscript published online 9 January 2020 https://ec.bioscientifica.com https://doi.org/10.1530/EC-19-0467 (c) 2020 The authors Published by Bioscientifica Ltd
This work is licensed under a Creative Commons Attribution-NonCommercial-NoDerivatives 4.0 elnternationad ticense ifica . com at 04/26/2023 09:58:42AM 